\title{
A CELEBRIZAÇÃo COMO SUCESSORA DO CARISMA OU COMO CONTRAPARTIDA SECULAR? O PAPEL DOS FAMOSOS NA SOCIEDADE CONTEMPORÂNEA
}

João KAMRADT*

\begin{abstract}
RESUMO: Este artigo busca compreender qual o papel do carisma na sociedade contemporânea e qual sua relação com as celebridades - indivíduos que atualmente são responsáveis por concentrar a atenção da sociedade. O carisma, na concepção weberiana, é entendido como uma qualidade de poucos indivíduos, vista como algo mágico, extracotidiano, responsável por dar legitimidade ao líder. A celebridade é um sujeito que ascendeu ao estrelato sem, necessariamente, ter nenhuma qualidade que não seja a de ser conhecido por um grande número de pessoas. Com o declínio das religiões e a diminuição da importância dada aos líderes políticos/religiosos, viso compreender se e até que ponto as celebridades incorporaram elementos típicos da conduta dos líderes carismáticos, se as celebridades são uma forma moderna de carisma, se o carisma weberiano é um conceito datado, não servindo para analisar o atual tempo, ou se continua tendo seu espaço na atual conjectura.
\end{abstract}

PALAVRAS-CHAVE: Celebridades. Carisma. Weber. Cultura Popular. Mídia.

\section{Introdução}

Em uma sociedade de mudanças constantes e ininterruptas, as celebridades se tornaram uma banalidade, sendo uma característica essencial da cultura ocidental. Transitando pelos mais distintos campos sociais, como o campo cultural, político e econômico, os famosos são um recurso essencial para que se expresse uma forma

Faculdade lelusc. Departamento de Ensino Superior. Joinville - SC - Brasil. 89221-665 joaokamradt@gmail.com. https://orcid.org/0000-0002-6440-8043. 


\section{João Kamradt}

de poder ou mesmo um caminho para a demonstração do poder. As celebridades também são fruto do declínio pelo qual passou a religião no século passado, que aliado à uma intensa industrialização e a democratização da sociedade, acabou gerando uma estrutura social mais fluída, em que há menos distinções sociais e que deu "aos indivíduos as condições para se superarem" (GABLER, 2000, p. 194). Se as celebridades ascenderam na sociedade, o carisma weberiano como uma forma legitimadora de poder, oriunda de um elemento extracotidiano acabou perdendo espaço e sendo relegado a espaços religiosos e/ou mágicos. Essa diferente percepção pela qual o carisma na clássica definição de Weber (2012) passa atualmente, aliada ao avanço das celebridades, gera os questionamentos deste artigo: seria a celebrização uma sucessora moderna do carisma, em sua definição weberiana, incorporando elementos antes presentes apenas na conduta de líderes carismáticos? Ou a celebrização funciona como um complemento secular do conceito de carisma? Outra hipótese é de que o conceito de carisma seja um conceito datado, não servindo para analisar a atual sociedade.

\section{O carisma em Weber}

As celebridades seriam sucessoras do líder carismático, no sentido weberiano, ou funcionariam como contrapartida secular? Para chegarmos a uma resposta para este problema, precisamos compreender melhor os conceitos de carisma e de celebrização. Em Weber (2012, p. 160), o poder carismático vai além das exigências da vida econômica, sendo contraponto às estruturas burocráticas e patriarcais - que servem a economia e as necessidades cotidianas. Essa face antieconômica é uma das principais características do conceito de carisma. Isso porque o carisma puro é contrário a toda economia ordenada e não seria uma forma de alcançar ganhos financeiros. Embora viva neste mundo, o carisma não viveria dele (WEBER, 2012, p. 161). Weber enxerga o carisma como revolucionário e transformador das ordens e das coisas, sempre de acordo com a vontade revolucionária (WEBER, 2012, p. 162). Esse caráter de mudança é central, sendo uma das principais alterações de características impostas pelo carisma. Como o carisma é para Weber um poder revolucionário capaz de criar a história, poderia romper com todos os tipos de normas da tradição que impõe uma sujeição íntima que ainda não havia sido vista.

Para Weber (2012), o surgimento da autoridade carismática não representa uma situação com falta de estrutura. Ao invés disso, é uma formação social com estrutura clara, baseada na vida comunitária do líder carismático ao lado dos seus

\footnotetext{
Todas as passagens em outra língua, foram traduzidas pelo autor do texto.
} 


\section{A celebrização como sucessora do carisma ou como contrapartida secular? O papel dos famosos na sociedade contemporânea}

seguidores. Nessa lógica, qualquer mudança que ocorrer na estrutura, como o desvio de costumes, irá atrapalhar a pureza da disposição carismática e conduzirá a outras formas estruturais. Caso aqueles que seguem o líder carismático parem de reconhecer a sua missão, o líder irá fracassar. Agora, caso continuem o reconhecendo, o líder mantém a união de seus seguidores, sempre mediante a apresentação de provas. $\mathrm{O}$ reconhecimento do carisma é qualificado pelo dever daqueles aos quais sua missão se dirige (WEBER, 2012). Nessa lógica, afirmar que o carisma só existe, seja na instituição ou no indivíduo, por meio da relação do reconhecimento por parte de uma comunidade a qual the dá sentido, não é imperativo. Weber (2012, p. 158) reconhece que "apesar de as capacidades carismáticas não poderem desenvolver-se em nada e em ninguém que não as possua em germe, tal germe permanece oculto se não é estimulado ao desenvolvimento, se o carisma não é 'despertado"'. Isso quer dizer que, caso não se reconheça a existência de um carisma presente em certos indivíduos, este se tornará carismático no momento no qual for colocado à prova diante da sua comunidade.

O líder carismático possui legitimidade não pela tradição de cargos ou por algum tipo de autoridade pré-estabelecida da posição social a que ocupa. É o contrário que ocorre. O portador de dons carismáticos (seja em forma inicial, pura ou ainda não rotinizada) irá se opor a todo tipo de manutenção do cotidiano. Mas, como dito, quem lidera algum tipo de comunidade irá ter que provar constantemente que sua missão possui algo de extracotidiano, de transcendente. A prova dos dons carismáticos é um fator fundamental para a manutenção da dominação carismática, já que sem ela o portador não teria como ter o contínuo reconhecimento da comunidade e "ao acabar o reconhecimento do povo, o senhor é um simples homem particular e, se pretende ser mais, um usurpador culpável” (WEBER, 2012, p. 159).

Com o tempo, o carisma do líder também passa a ser rotinizado. Isso é inevitável na medida em que existe o desejo dos seguidores e dos dominados de que o líder carismático tente transformar o carisma em um elemento permanente da vida cotidiana. Quem segue os líderes busca satisfazer as necessidades econômicas que possui sem depender de um estilo de vida comunitário. Desse modo, a existência do carisma acaba sendo subvertida pelo domínio do cotidiano. Weber (2012) deixa claro que o carisma possui um elemento individual, sendo determinado por fatores internos e alheios a economia. Assim, a dominação carismática se dá na medida em que os seguidores do líder reconhecem sua missão. Esse reconhecimento não é o principal argumento de sua legitimidade, já que antes os indivíduos reconheceram essa qualidade em virtude da vocação do líder e das contínuas provas do seu carisma. Caso as pessoas não reconheçam mais seu carisma, o líder acaba fracassando. Por sua vez, se a missão é reconhecida, o líder continua dominando (WEBER, 2012). 


\section{Joāo Kamradt}

\section{O conceito de liderança carismática reconsiderado}

O conceito de carisma weberiano gera debate principalmente quanto à possibilidade ou não de ser aplicado para compreender a política contemporânea. Alguns comentadores se impressionam com o poder e a potencialidade do termo para analisar situações de lideranças do passado e do presente histórico. Mas outros são céticos quanto a ideia de utilizar o conceito atualmente. Teria sido o carisma substituído por outras formas de representatividade, como a celebrização dos indivíduos? Foi Loewenstein (1966) o responsável por levantar a questão sobre se o carisma poderia ser aplicado para compreender a política contemporânea. Segundo ele, a liderança carismática depende de uma ampla crença na existência de capacidades extraordinárias ou sobrenaturais, mas essa crença perde força em contextos seculares. Ele argumenta que embora a democratização tenha aumentado o componente plebiscitário dentro da política moderna, as qualidades do indivíduo que atraem os eleitores indicam a popularidade, mas isso não representa necessariamente o carisma de um líder político bem-sucedido. Sendo assim, Loewenstein afirmou de forma emblemática: "na política, o carisma é um fenômeno do mundo précartesiano" (LOEWENSTEIN, 1966, p. 86). Ele compreende que as áreas em que existe uma crença maior no sobrenatural (ele cita como exemplo regiões da Ásia e da África) teriam uma propensão maior para encontrar líderes carismáticos.

Outra crítica recorrente foi feita por Schlesinger (1960). Segundo ele, o uso que Weber fez do carisma demonstra "sua irrelevância para o mundo técnico moderno", sendo algo "especificamente fora do âmbito da rotina diária" (SCHLESINGER, 1960, p. 6) e, também, irracional. Desse modo, alega que devido à natureza da sociedade moderna, não é possível utilizar o carisma para analisar a liderança moderna. Friedrich (1961) defendeu uma interpretação restritiva do conceito. Segundo ele, Sohm, de quem Weber derivou o termo e a ideia de carisma, argumenta que a liderança carismática é uma liderança baseada em um chamado transcendental feito por um ser divino no qual tanto a pessoa chamada quanto seus seguidores passam a acreditar. Friedrich (1961) sente que essa liderança carismática precisa ser concebida na fé em Deus ou em deuses. Ele aponta que Weber alargou o conceito para incluir tipos seculares e não-transcendentais, inspirados no líder do tipo demagógico.

Há os que defendem a aplicação do conceito para interpretar a política contemporânea. Shils (1965), por exemplo, enxerga a autoridade carismática em todas as sociedades. Ele argumenta que Weber faz distinção entre os efeitos inovadores do carisma e o caráter rotineiro da tradição ou da ordem legal. Aponta que o sociólogo alemão não teria limitado o uso do termo a crenças mágicas ou religiosas, tendo também analisado a institucionalização do carisma através do parentesco e da hereditariedade. Mesmo assim, Weber compreende que as oportunidades de carisma 


\section{A celebrização como sucessora do carisma ou como contrapartida secular? O papel dos famosos na sociedade contemporânea}

genuíno diminuíram em conformidade à crescente racionalização e burocratização da sociedade ocidental. Shils (1965) questiona isso. Ele alega que as sociedades enfrentam exigências que necessitam de soluções nas quais o carisma seja atribuído aos indivíduos e as instituições que prometem satisfazer essa necessidade.

O debate em torno da possibilidade ou não do conceito de carisma ser utilizado atualmente torna necessário um retorno às formas como Weber usou o termo. Breuilly (2011) empreendeu essa tarefa. Segundo ele, Weber utiliza o conceito de carisma de três formas distintas. Antes de 1914, com a publicação da parte II de Economia e Sociedade, Weber fornece exemplos, a maioria vinda de sociedades pré-modernas, nos quais menciona figuras como senhores de guerra, caciques de caça, demagogos de cidades-estados e indivíduos aos quais foram atribuídos poderes mágicos. Em um segundo momento, nos escritos políticos, durante e logo após a Primeira Guerra Mundial, Weber se centrou na liderança carismática em uma concepção moderna, especialmente aquela formada por líderes eleitos advindos de partidos políticos, sendo parte dos esforços voltados para compreender como a Alemanha poderia encontrar uma liderança dinâmica que suprisse as necessidades da nação. Em um último ponto, nos escritos pós-guerra, publicados como uma parte de Economia e Sociedade, Weber desenvolveu o conceito de autoridade carismática como uma das formas ideais de dominação praticadas pelas sociedades ou pelos indivíduos. Assim, foi possível analisar relacionamentos sociais em um conceito histórico. De todo modo, Breuilly (2011) entende que o carisma possui uma faceta pré-moderna, precisando ser reelaborado para funcionar atualmente. Ele argumenta que os escritos weberianos sugerem dois tipos de dominação carismática, sendo o segundo compreendido como uma forma de ligação entre o conceito weberiano de carisma e a celebrização dos políticos modernos. Breuilly (2011) descreve os tipos da seguinte forma:

O primeiro deles é encontrado em sociedades tradicionais de pequena escala com crenças amplamente difundidas sobre a existência de poderes transcendentes além do mundo mundano que podem ser exploradas e concentradas pelos indivíduos. No que diz respeito ao nacionalismo moderno, esse poder carismático pode ser organizado no espaço entre a autoridade tradicional de pequena escala e o estado colonial em larga escala. O segundo tipo de dominação carismática se desenvolve em estados-nação modernos com fortes sentimentos nacionalistas existentes onde uma crise maciça tem minado as modernas instituições de poder. É com base nessa ideologia nacionalista, ligada à noção de gênio - uma espécie de moderno secular, equivalente à ideia do sagrado - que um líder carismático pode emergir. Em seguida, o aparelho burocrático do poder do Estado moderno pode ampliar ao invés de corroer tal carisma (BREUILLY, 2011, p. 492). 


\section{João Kamradt}

Como Tucker (1968) aponta, não é fácil distinguir entre líderes que são carismáticos e líderes que não possuem o carisma no sentido weberiano. Ele observa que Weber não fornece uma declaração clara e nem elenca as qualidades pessoais que os líderes carismáticos precisam ter para dar origem a um vínculo emocional especial com seus seguidores. "Em suma, a teoria da liderança carismática, como o próprio Weber expôs, nos deixa em dúvida sobre quais líderes são carismáticos e o que os torna assim" (TUCKER, 1968, p. 734). Tucker (1968) ainda aponta que embora o carisma seja um fenômeno de significado universal, as manifestações políticas são apenas uma de suas múltiplas dimensões. Segundo ele, quando Weber utiliza o termo, o usa de maneira neutra em termos de valores. Desse modo, ele diz que um líder carismático não precisa necessariamente ser admirável.

Tucker $(1968$, p. 741$)$ defende que uma regra geral das lideranças carismáticas é de que "quando uma personalidade-líder é genuinamente carismática, seu carisma começará a se manifestar antes que ele se torne politicamente poderoso". O específico na resposta carismática não é a obediência absoluta ao líder, mas simplesmente o fato de que por força de qualidades extraordinárias ele exerce uma dominação sobre os seus seguidores.

Seguidores podem estar sob o feitiço de um líder e podem aceitá-lo como uma autoridade suprema, sem necessariamente concordar com ele em todas as ocasiões. Na atmosfera altamente argumentativa de um partido radical moderno, por exemplo, um líder pode ser carismático e contestado em pontos específicos. De fato, ele pode até manifestar seu carisma de maneira inspirada pela qual conquista a dissidência pelo poder absoluto de seu discurso político (TUCKER, 1968, p. 736).

Não devemos, portanto, considerar a relação de autoridade carismática como aquela que envolve a obediência automática dos seguidores às ideias do líder ou excluir a possibilidade de que os seguidores ocasionalmente discordem do líder. Ainda mais que além de ser considerado um inovador, o líder carismático tenha predisposição a romper com os modos estabelecidos de pensar e agir, assumindo posições que divergem das expectativas dos seus seguidores e que acabam levantando questões incômodas. Kalivas (2002) alega que parte dos pesquisadores que estudam o carisma weberiano reconhecem o poder desse tipo de líder, mas enfatizam sempre um caráter emocional que levaria a uma "celebração do irracionalismo". Posição ao qual se opõe e utiliza para demonstrar que o carisma não possui padrão claro de manifestação.

Em suma, não acreditamos que exista um contexto usual ou necessário dentro do qual o carisma se desenvolva naturalmente. A situação em que tal movimento 


\section{A celebrização como sucessora do carisma ou como contrapartida secular? O papel dos famosos na sociedade contemporânea}

ocorre pode ser relativamente ordenada ou pode envolver desordem militar, política e econômica. Em ambos os casos, mas particularmente no último, tais situações não produziram uniformemente uma disputa revolucionária, um ideal e resultaram tanto em soluções não-carismáticas quanto em soluções carismáticas. Assim, qualquer análise que se concentre exclusivamente no contexto social em que o carisma supostamente se desenvolve, corre o risco de interpretar erroneamente a natureza fundamental do movimento carismático, isto é, a independência relativa tanto do indivíduo excepcional quanto de suas ideias. Isso não significa que o homem ou suas ideias são agentes livres no processo de transformação histórica, mas apenas que eles são mais autônomos (KALIVAS, 2002, p. 309).

Propriedades mágicas e transcendentais. Qualidades extraordinárias. Dominação dos súditos. Elementos do mundo pré-cartesiano. O carisma, na definição dada por Weber, não indica poder ser aplicado plenamente na sociedade contemporânea. Diante deste quadro, uma hipótese é de que a liderança carismática esteja sendo representada pelas pessoas famosas da sociedade contemporânea: as celebridades. Para Turner (2003, p. 24), isso não só é possível como também se tornou algo trivial. Segundo ele, vivemos na cultura de celebridades e a celebridade por si só já é um conceito que apresenta similaridade e um avanço em relação ao conceito de carisma proposto por Weber.

\section{Celebridades prosperam no seio da sociedade moderna}

Qualquer celebridade é carismática? A celebridade seria uma forma de democratizar o carisma? Como elas se tornaram elementos centrais da sociedade? Embora as celebridades tenham se tornado elementos essenciais na sociedade midiática, nem sempre o cenário se desenhou desta forma. A primeira vez que o termo celebridade foi aplicado para designar uma pessoa foi em 1849, segundo o The English Oxford Dictionary (2010). Segundo o dicionário, a palavra celebridade seria "a condição de ser exaltado ou falado; fama, notoriedade"; "pessoa de celebridade; pessoa celebrada; uma figura pública". Ao traçar e comparar a origem do termo em inglês, Marshall (2008) mostra como essa aplicação é diferente da dada até então. Analisando outros dicionários ingleses da época (Webster's e Oxford English), ele mostra significados distintos: em alguns momentos, celebridade era interpretada como "um rito solene ou cerimônia, celebração", em outros como o "respeito devido aos cultos e cerimônias, pompa, solenidade". Ainda hoje vemos diferenças de interpretações. O dicionário Aurélio (2011) apresenta celebridade em termos de "notabilidade, pessoa célebre", "coisa extraordinária, fama e renome". 


\section{João Kamradt}

Com o surgimento e o crescimento da cultura de celebridades se tornou possível compreender como, a partir de 1900, se produzia uma celebridade. Primeiro nos EUA, depois no resto do mundo, o rosto ou o nome de um indivíduo podia se tornar familiar para toda uma nação em questão de horas. Como Ortiz (2016) destaca, a revolução gráfica foi importante por dar a qualquer indivíduo a possibilidade de se tornar conhecido. Mas isso não significa que qualquer famoso se torna uma celebridade. Schickel (1985) atribuiu ao espaço maior dado à mídia ao longo do último século o surgimento das celebridades como as conhecemos hoje. Ruebsaat (2007) e Leslie (2011) seguiram o mesmo caminho ao afirmar que a celebridade foi concebida pelo cruzamento entre a mídia moderna e o processo de democratização da sociedade. No caso dos dois, o surgimento das celebridades ocorreria em paralelo ao nascimento da fotografia, no começo do século XIX. Como Ortiz (2016, p. 672) descreve: "a invenção da fotografia e do cinema, a proliferação da imprensa de massa, o surgimento da publicidade moderna, o advento do rádio e da televisão tornam-se elementos imprescindíveis para a constituição de uma celebrity culture". Boorstin (1971) afirma que isso fez com que consumidores da mídia pudessem celebrar a grandeza de um indivíduo pelo fato de ele estar na mídia de massa.

Celebridades são indivíduos que passam por um constante processo de visibilidade, sendo produtos da modernidade. Para Antoine Lilti (2014), as celebridades foram inventadas entre 1750 e 1850 . Ele data o século XVIII como o embrião para o surgimento de uma sociedade do espetáculo nas quais as características físicas e de personalidade de certos atores ou atrizes ${ }^{2}$ do teatro, de músicos, de políticos e de escritores acabou sendo projetada na arena pública. Para Boorstin (1971), uma celebridade "não faz nada" de excepcional, não realiza nada. Sua grande qualidade é a "ausência de qualidade". Rojek (2008) foi taxativo ao argumentar que as celebridades são um fenômeno moderno. Segundo ele, na sociedade contemporânea, o termo celebridade está associado a fama, à natureza temporária, volúvel e ao mercado de sentimentos humanos. Tudo em um contexto em que ocorrem relações episódicas, anônimas, em que há mudanças velozes na vida social e econômica do indivíduo, sustentadas pela atribuição de um status glamouroso a um sujeito dentro da esfera pública. Ortiz (2016) foi mais longe em sua definição ao afirmar que a celebridade possui todos os traços de uma individualidade ${ }^{3}$ única. "O estamento, a classe social, o pertencimento a um grupo tornam-se secundários (mas não apagados) diante da presença da idiossincrasia pessoal. O reconhecimento por sua vez pressupõe a existência de pessoas que

\footnotetext{
2 Segundo Lana (2013), no início do século XIX, mulheres celebrizadas eram, em quase todos os casos, aristocratas. Elas sabiam ler e escrever, tinham influência política e eram consideradas damas da sociedade.

3 Para Rojek (2008, p. 107), "o desejo de ser reconhecido como especial ou único talvez seja uma característica inevitável de culturas construídas em torno da ética do individualismo".
} 


\section{A celebrização como sucessora do carisma ou como contrapartida secular? O papel dos famosos na sociedade contemporânea}

possam identificá-la como "íntimos estranhos"” (ORTIZ, 2016, p. 675). Por sua vez, Rojek (2011) fala que:

(...) o significado moderno do termo celebridade, a bem dizer, deriva da queda dos deuses e da ascensão de governos democráticos e sociedades seculares. Não por acaso. A crescente importância do rosto público no dia-a-dia é uma consequência da ascensão da sociedade pública, uma sociedade que cultiva o estilo pessoal como antídoto para a igualdade democrática formal (ROJEK, 2008, p. 11).

A definição de Marshall (2008) sobre o conceito é clara. "Parece que o uso moderno do termo celebridade se vincula à valorização da cultura popular e da cultura democrática. A celebridade materializa o empoderamento do povo que simbolicamente constitui a esfera pública" (MARSHALL, 2008, p. 7). Isso faz Ortiz (2016, p. 685) afirmar que o status de celebridade apenas é confirmado no instante em que "o conteúdo da pessoa se torna secundário diante da sua representação pública".

Ainda relacionado à conceituação do termo celebridade, há a definição dada por Marshall (2008), de que os celebrizados são um "grupo de indivíduos" que possuem grande presença e mais abrangência do que o resto da população, compondo um "sistema de valorização do significado e da comunicação" (MARSHALL, 2008, p. ix-x). Hollander (2010) oferece outra característica interessante para explicar o surgimento das celebridades na sociedade moderna. Além de citar que o culto ao individualismo foi essencial para o surgimento das pessoas célebres, ele aponta que as celebridades ajudam "a convencer as pessoas de que para se ascender ao status de celebridade não há necessidade de se possuir nenhum talento ou qualificação especial" (HOLLANDER, 2010, p. 390).

Com um conceito delineado, é preciso reforçar que as celebridades são parte de três grandes processos históricos: 1) o declínio da religião organizada, ou seja, o processo de secularização ${ }^{4}$ narrado por Weber $(2012)$; 2) a democratização de todos os aspectos da sociedade; e 3) a industrialização e consequente transformação do cotidiano em mercadoria (ROJEK, 2008, p. 15). Como ele explica:

(...) o declínio da sociedade cortesã dos séculos XVII e XVIII implicou a transferência de capital cultural para homens e mulheres que venciam pelo próprio esforço. Com o desenvolvimento da sociedade moderna, as celebridades preencheram a ausência gerada pela decadência da crença popular no direito divino dos reis e da morte de Deus (ROJEK, 2008, p. 15-16).

${ }_{4}$ Como Sell (2015, p. 12) afirma, a secularização é "uma tentativa de compreensão da natureza do moderno em sua relação histórica com o religioso". 
Caminho semelhante ao percorrido por Marshall (2008), que além de citar a democratização da sociedade, usa o surgimento do capitalismo para explicar o motivo das celebridades formarem um grupo de poucos indivíduos ${ }^{5}$. Segundo Marshall (2008), as celebridades têm sua origem ligada ao surgimento de populações urbano-industriais, sendo uma "tentativa de conter a massa". Ele argumenta que isso foi feito através do uso de símbolos. Ou seja, modelos que seriam apresentados ao público. Assim, os indivíduos seriam encorajados a se identificar com esses modelos. Nessa lógica, as celebridades passam a funcionar como vigilantes da democracia ao irradiar glamour e atração e demonstram de forma automática que o sistema valoriza a mobilidade ascendente, premiando um tipo de talento bem específico: a capacidade de se celebrizar.

Como fenômeno moderno, as celebridades precisam ter sua imagem propagada imensamente através dos meios de comunicação de massa. Segundo Turner (2003, p. 3), uma das características dos famosos é de que "a celebridade moderna não pode reivindicar nenhuma realização especial para si além da atenção pública". Por sua vez, Thompson (2005, p. 220-225) argumentou que as celebridades possuem como característica fundamental possuir admiradores e fãs. Ele alega que as celebridades são um aspecto que define a modernidade, por implicar a necessidade da formação de relações de intimidade com indivíduos distantes e diferentes entre si. Esse elemento, segundo o autor, foi o que deu base para que as celebridades sejam vistas como uma forma de representação política. Como Street (2004) aponta, as celebridades criam vínculos afetivos com seus admiradores/seguidores e isso, em determinados contextos, torna possível que um artista ou que um político celebrizado reivindique aqueles que o admiram. "Eles dão voz política aos que os seguem, tanto em virtude das condições políticas quanto por meio de sua arte" (STREET, 2004, p. 449). Segundo Wheeler (2012, p. 408), “os deveres cívicos tradicionais estão sendo substituídos por formas alternativas de participação. Dentro deste novo ambiente político, diferentes tipos de agência, como a política de celebridade, tornaram-se forças centrífugas para o engajamento público".

\section{Celebridades: herdeiras modernas do carisma?}

A convergência entre carisma e celebridade dentro de um sistema simbólico não foi explicada nas teorias da cultura de celebridades propostas por Rojek (2008) e Marshall (2008). Para esses autores, a celebridade é uma contrapartida secular, sendo até mesmo considerada uma sucessora do carisma, implicando em uma

5 Como apontam Bonner et al. (1999, p. 56), a "celebridade não existe como uma propriedade de indivíduos específicos; mais do que isso, ela é constituída discursivamente através do modo como os indivíduos são representados". 


\section{A celebrização como sucessora do carisma ou como contrapartida secular? O papel dos famosos na sociedade contemporânea}

diferença marcada e até mesmo teleológica entre os tipos de distinção social e de prestígio.

Em discussão sobre a produção de poder simbólico na política da Indonésia, a antropóloga Hughes-Freeland (2007) apontou que a celebridade não necessariamente substitui o carisma. Segundo ela, "símbolos sacros e seculares engajam-se à celebridade em termos de representação e estilo pessoal, mas os cultos da personalidade exploram características carismáticas ou de celebridades de acordo com os padrões das relações sociais nas quais estão situados" (HUGHES-FREELAND 2007, p. 193). Seu estudo examina como líderes políticos adotaram o comportamento comum a integrantes do show business em ambientes sociais específicos. Com o tempo, o status público desses líderes políticos passou a carregar as qualidades carismática e de celebrização. Ainda assim, significativamente, Hughes-Freeland (2007) localizou o carisma dentro do domínio político ao mesmo tempo em que alocou celebridade dentro da esfera do entretenimento e da cultura popular.

Na perspectiva de Pype (2009), a co-ocorrência de ambos os mecanismos de distinção social não apenas diferiu da distinção feita por Rojek (2008) e Marshall (2008), mas também da realizada por Hughes-Freeland (2007). Pype (2009) argumentou que no caso das figuras públicas cuja publicidade deriva da mídia de massa e que também possuem alegados poderes sobrenaturais, os elementos carismáticos e celebrizados se fundem. De acordo com Weber (2012), uma das maneiras pelas quais as comunidades respondem à erosão dos costumes, tradições e instituições anteriormente autorizadas foi através do carisma vindo de atributos pessoais de indivíduos únicos. Weber (2012) acreditava que, mesmo em uma sociedade moderna, o carisma permanecia relevante como uma forma externa de legitimação. Embora historicamente o carisma fosse baseado em heroísmo ou revelação, ele pode adquirir diferentes formas culturais em um contexto moderno. As celebridades podem não possuir qualidades heroicas, mas como modelos altamente visíveis, elas se tornaram objeto de imitação. Aqui estaria uma relação de continuidade entre carisma e celebridade. A personalidade altamente divulgada da celebridade e as qualidades individuais funcionam de forma similar ao carisma, possuindo a qualidade de chamar a atenção das pessoas. Friedman $(1994$, p. 78) foi taxativo ao afirmar que a dominação carismática "foi remodelada na imagem da celebridade".

Com base nos recursos culturais da política de celebridades, figuras públicas e até líderes religiosos tentaram cultivar uma imagem de persona popular pública acessível. Como Furedi (2010) detalha, até mesmo o papado internalizou elementos dessa influência. A grande multidão de jovens atraídos para o funeral do papa João Paulo II, em abril de 2005, ficou fascinada com a imagem do superastro religioso e tratou o evento como se fosse um festival de música pop. 


\section{João Kamradt}

As celebridades de hoje podem não ter as qualidades mágicas tradicionalmente associadas ao status de carisma. E, de fato, muitas vezes eles aparecem como o oposto desse tipo ideal weberiano. No entanto, sua fama os destaca como únicos e diferentes das pessoas comuns "que não são conhecidas". Estes são indivíduos que através de algum tipo de processo mágico se tornaram uma versão exaltada de nós mesmos. Sua autoridade não reside tanto em suas qualidades superiores, mas no fato de que elas servem como um ponto de referência para os outros. Em particular, eles servem como modelos para o comportamento expressivo (FUREDI, 2010, p. 495).

Ainda segundo Furedi (2010), assim como eram as figuras carismáticas clássicas, as celebridades são indivíduos que fornecem às pessoas comuns um foco de identificação. Mas, ao contrário dos indivíduos carismáticos, as celebridades carecem das misteriosas qualidades de liderança transcendentais vistas em um profeta ou um herói. Elas são modelos ao invés de líderes autorizados.

\section{Convergência e divergência na relação entre os conceitos de carisma e de celebridade}

O carisma e a celebridade são atribuídos a pessoas de amplo reconhecimento público, que possuem reputações ampliadas, embora em estilos e contextos diferentes. "Carisma" foi o termo usado por Weber (2012) para se referir ao "dom extraordinário e pessoal da graça" associado em sua forma pura como "dominação carismática". O conceito foi diferenciado de dois outros tipos puros de dominação: a racional-legal ${ }^{6}$ e a tradicional ${ }^{7}$. Celebridade é "a atribuição de glamour ou

\footnotetext{
6 A dominação racional-legal está baseada na legalidade que é defendida por estatutos e normas jurídicas, possuindo entre seus objetivos as seguintes características: a) o soberano não exerce o mandato de acordo com o seu arbítrio. Ele está subordinado a leis conforme as quais pauta os seus atos; b) a obediência ao soberano não é compreendida como uma obediência ao indivíduo, mas sim a uma ordem impessoal; c) existe uma separação entre o que é patrimônio público e o que é patrimônio privado. Ou seja, os funcionários não irão se apropriar dos cargos em que estão e estão sujeitos à prestação de contas com os cidadãos; d) o sistema é regido pelas hierarquias administrativas e pelo princípio da competência; e) cada tipo de autoridade tem atribuído um conjunto de funções; f) os "casos" são resolvidos de acordo com a aplicação de regras técnicas e de normas; g) é exigido dos funcionários um saber profissional específico. Do mesmo modo, o recrutamento desses indivíduos é realizado de modo competitivo, sendo levado em conta o mérito e a capacidade de cada um dos candidatos.

7 O segundo tipo ideal seria a dominação tradicional, que para Weber é essencialmente pessoal. Esta é fundamentada na crença na legitimidade que o soberano possui advinda da tradição para poder exercer o seu governo. Nesse tipo de dominação, não há uma norma racional e objetiva ou regra, do mesmo modo que não há uma criação deliberada de estatutos administrativos ou jurídicos. Os dominados precisam obedecer a pessoa do soberano, sendo servos dele. "Denominamos uma dominação tradicional quando sua legitimidade repousa na crença da santidade de ordens e poderes senhoriais tradicionais ("existentes desde sempre"). Determina-se o senhor (ou os vários senhores)
} 


\section{A celebrização como sucessora do carisma ou como contrapartida secular? O papel dos famosos na sociedade contemporânea}

status notório a um indivíduo dentro da esfera pública" (ROJEK, 2008, p. 10). Uma leitura estritamente evolucionista de Weber (2012) conceitua o carisma e a legitimidade como mutuamente exclusivos, mas isso resulta de uma simplificação exagerada da relação do carisma com a dominação racional-legal e tradicional. Como Hughes-Freeland (2007) demonstra, uma leitura de Weber que atende à sua descrição da "rotinização do carisma", frequentemente deixada de lado nos relatos culturais de poder e de liderança e nas abordagens teóricas da celebridade ajuda a explicar o papel da celebridade na política moderna. Ela defende que as contradições e indeterminações de Weber em relação ao significado e racionalidade produzem um modelo para entender diversos estilos culturais. Segundo ela, o carisma e a celebridade podem expressar diferentes racionalidades e não precisam ser conceitualizados em relação ao que foi descrito como um sistema individualista "pós-Deus" (ROJEK, 2008). "Em vez disso, a celebridade se entrelaça com o carisma e articula um relacionamento complexo entre os tipos tradicionais e legais de autoridade de Weber" (HUGHES-FREELAND, 2010, p. 198).

Reconhecer o papel da celebridade dentro do processo político não leva necessariamente a que o carisma weberiano seja visto como relevante para a celebridade moderna. Rojek (2008) e Marshall (2008) leram Weber para produzir duas abordagens contrastantes para o papel do carisma na conceituação do que é celebridade. Rojek (2008) invoca as categorias ideais de Weber, mas descarta sua teoria como subjetivista. Em uma sociedade em que a racionalidade foi tomada como garantida, o carisma se constitui como uma qualidade exclusivamente pessoal reservada aos líderes religiosos (ROJEK, 2008). Nessa lógica, a celebridade teria assumido um sentido mais amplo do que carisma ao satisfazer desejos decorrentes do vácuo deixado pelo declínio da religião organizada, ao mesmo tempo em que continuou recorrendo a narrativas religiosas e a simbologias. Para Rojek (2008, p. 97), a celebridade não é um substituto para a religião, mas "o meio em que o reconhecimento religioso e a pertença são agora promulgados". Enquanto isso, o carisma foi considerado irrelevante para criar relações sociais fora da esfera religiosa.

Marshall (2008) possui uma abordagem contrastante ao analisar a celebridade, assim como o carisma, como uma parte do processo de racionalização. Para Marshall (2008), o carisma é rotinizado não como racionalidade no sentido weberiano, mas como uma "racionalidade afetiva". Essa racionalidade deriva do "poder afetivo" da circulação da vigilância visto no panóptico burocrático de Foucault (2002). A racionalidade afetiva é responsável pela dimensão pessoal da celebridade. Como a sexualidade, ela é vivenciada de maneira muito pessoal e íntima, mas dentro de uma

em virtude de regras tradicionais. A ele se obedece em virtude da dignidade pessoal que the atribui a tradição" (WEBER, 2012, p. 148). 
estrutura representacional: "O sistema de celebridades constitui uma técnica para a organização do investimento cultural nos atributos de personalidade e sentimento, subjetividade individual e experiência privada”. (MARSHALL, 2008, p. 75).

A racionalidade afetiva foi demonstrada em respostas em massa a celebridades do entretenimento e líderes políticos, especialmente em épocas de eleição. O status de celebridade é uma fonte de poder compartilhada por políticos e estrelas, "um sistema unificado", no qual "a aprovação do poder é baseada em emoções semelhantes, sentimentos irracionais, ainda que culturalmente estejam profundamente enraizados" (MARSHALL, 2008, p. 19). Aqui, a rotinização do carisma explica a manifestação dos "cultos de personalidade" nos sistemas políticos racionais, demonstrando que a política nunca é inteiramente racional, embora Marshall (2008, p. 277) assim como o próprio Weber, pergunte se a importância do afeto na organização da subjetividade pública não pode ser "evidência de uma crise de legitimação nas democracias capitalistas". A rotinização, no entanto, despersonaliza o carisma e transforma as qualidades pessoais em papéis. Seguindo a sociologia de Weber (2012), o carisma não é uma qualidade individual, mas sim produzido de forma relacional através da manutenção de seguidores dentro do processo político.

Essa análise acaba minimizando as contradições na rotinização do carisma e argumentando que qualquer irracionalidade residual deve ser redutível à racionalidade. Esses dois relatos mostram que a celebridade é uma pré-condição contínua para as formações políticas, o que leva ao "carisma objetivado" de Weber (2012), à transformação social e, provavelmente, à integração social. Rojek (2008, p. 203) criticou o tratamento conservador de Marshall (2008) ao consumismo como uma forma de subordinação política na qual as celebridades estariam "congelando a massa", mas também argumentou que, embora alguns famosos interrompam a ordem social, a celebridade é "uma instituição significativa na normatização" da integração social. No entanto, onde Rojek (2008) molda o carisma como uma forma de "alternância teórica", a ênfase de Marshall (2008) se dá no aspecto relacional do carisma como uma troca social entre líderes e seguidores que articulam a semelhança entre carisma e celebridade. Ambos envolvidos em um processo de transações representacionais que confirmam o status e a reputação de um indivíduo usando símbolos seculares e não seculares.

\section{Considerações finais}

Este artigo buscou debater se a celebridade pode ser considerada uma sucessora ou uma outra faceta do conceito weberiano de carisma. De antemão, se constatou que a congruência entre carisma e celebridade oferece um caminho 


\section{A celebrização como sucessora do carisma ou como contrapartida secular? O papel dos famosos na sociedade contemporânea}

útil para uma abordagem antropológica da celebridade no campo político. Como Hughes-Freeland (2010) diz:

O conceito de carisma de Weber objetivado e rotinizado dentro de estruturas que se baseiam na autoridade tradicional e racional é útil para explicar como as pessoas (...) consideram seus líderes. A liderança carismática é uma relação social que inclui o poder de atrair seguidores, tanto em épocas de mudança de regime e crise quanto rotineiramente, quando o carisma se torna parte de metáforas legitimadoras e continuidades sustentáveis (HUGHES-FREELAND, 2010, p. 192).

Hughes Freeland (2010) sugere que a discussão de Weber sobre o carisma em relação à sua rotinização também permite refletir criticamente sobre o desenvolvimento do conceito de celebridade. Ela entende que a celebridade é uma nova forma de "carisma objetivado", mas não necessariamente o substitui. O carisma rotineiro e o simbolismo tradicional são produzidos pelas celebridades através da mídia impressa, televisiva e digital, apresentando um estilo de populismo que cria uma sobreposição, seja entre instituições tradicionais e racionais, seja entre políticas autoritárias e políticas democráticas. Poderes sacro e secular acabam sendo aspectos diferentes do processo político, não constituindo fases evolutivas.

É possível assinalar que assim como o carisma, as celebridades também teriam um caráter revolucionário ao transformar as ordens e ao conseguir impor sua opinião e/ou vontade a um grande contingente de indivíduos. Além de possuir um caráter democrático, sendo composta por indivíduos de todas as classes, etnias e gêneros. Mesmo assim, a interpretação do sucesso ou não do uso de um líder carismático feita por Tucker (1968), também pode ser aplicada as celebridades na atual sociedade. Segundo ele, um líder carismático não seria qualquer líder que fosse idolatrado e livremente seguido por suas extraordinárias qualidades de liderança, mas alguém que demonstrasse essas qualidades no processo de convocação de pessoas para participar de uma mudança e que conseguisse liderar esse movimento.

Como se vê atualmente, celebridades possuem amplitude para convocar multidões, seja para movimentos políticos ou culturais. $\mathrm{O}$ acesso direto dos fãs que as celebridades têm por meio de suas contas pessoais (principalmente por redes sociais como o Facebook, Instagram, SnapChat e Twitter) tornou possível que em pouco tempo um famoso reúna seus seguidores em torno de uma causa. Diante da complementaridade entre os conceitos de carisma e de celebridade, torna-se necessária a produção de novos estudos que visem explorar as mais diferentes facetas de como os indivíduos celebrizados se comportam na sociedade contemporânea e de como influenciam outros indivíduos e suas decisões. 


\title{
The CELEBRATISING AS A SUCCESSOR OF THE CHARISM OR AS A SECULAR COUNTERPART? THE ROLE OF CELEBRITIES IN CONTEMPORARY SOCIETY
}

\begin{abstract}
This article seeks to understand the role of charisma in contemporary society and its relationship with celebrities - individuals who are currently responsible for focusing the attention of society. Charism, in its Weberian conception, is understood as a quality of few individuals, seen as something magical, extraquotidian, responsible for giving legitimacy to the leader. The celebrity is a subject who has risen to stardom without necessarily having any quality other than to be known by a large number of people. With the decline of religions and the diminished importance given to political / religious leaders, this article aims to understand if and to what extent celebrities have incorporated elements typical of the behavior of charismatic leaders, also if celebrities are a modern form of charisma, whether the Weberian charisma is an outdated concept, unable to be used to analyze the current time, or if it continues having its space in the current conjecture.
\end{abstract}

KEYWORDS: Celebrities. Charisma. Weber. Popular culture. Media.

\section{¿CElebración COMO SUCESOR DEL CARISMa O COMO CONTRAPARTE SECULAR? EL PAPEL DE LOS FAMOSOS EN LA SOCIEDAD CONTEMPORÁNEA}

RESUMEN: Este artículo busca entender el papel del carisma en la sociedad contemporánea y su relación con las celebridades - individuos que actualmente son responsables de centrar la atención de la sociedad. El carisma, en la concepción weberiana, se entiende como una cualidad de unos pocos individuos, vista como algo mágico, extra-diario, responsable de dar legitimidad al líder. La celebridad es un sujeto que ha ascendido al estrellato sin tener necesariamente otra cualidad que la de ser conocido por un gran número de personas. Con el declive de las religiones y la disminución de la importancia otorgada a los líderes políticos/religiosos, me propongo comprender si y en qué medida las celebridades han incorporado elementos típicos de la conducta de los líderes carismáticos, si las celebridades son una forma moderna de carisma, si el carisma weberiano es un concepto anticuado, que no sirve para analizar el tiempo actual, o si sigue teniendo su espacio en la conjetura actual.

PALABRAS CLAVE: Celebridades. Carisma. Weber. Cultura popular. Medios de comunicación. 
A celebrização como sucessora do carisma ou como contrapartida secular? O papel dos famosos na sociedade contemporânea

\section{REFERÊNCIAS}

BONNER, F.; FARLEY, R.; MARSHALL, P.; TURNER, G. Celebrity and the media. Australian Journal of Communication, v. 26, n. 1, p. 55-70, 1999.

BOORSTIN, D. The image. A guide to pseudo-events in America. New York: Vintage Books, 1971.

BREUILLY, John. Max Weber, charisma and nationalist leadership. Nations and Nationalism, v. 17, n. 3, p. 477-499, 2011.

DICIONÁRIO. Aurélio. São Paulo: Editora Positivo, 2010.

DICIONÁRIO. The English Oxford Dictionary. Oxford: Oxford University Press, 2011. FOUCAULT, M. Vigiar e punir. Petrópolis: Vozes. 2002.

FUREDI, F. Celebrity Culture. Symposium: Celebrity around the world. Journal of Society, v. 47, p. 493-497, 2010.

FRIEDMAN, L. The republic of choice: Law, authority and culture. Cambridge: Harvard University Press, 1994.

FRIEDRICH, C. J. Man and His Government: An Empirical Theory of Politics. New York, 1961.

GABLER, N. Life: the Movie - How Entertainment Conquered Reality. New York: Vintage Books, 2000.

HOLLANDER, P. Why the celebrity cult? Sociology, v. 47, n. 5, p. 388-391, 2010.

HUGHES-FREELAND, F. Charisma and celebrity in Indonesian politics. Anthropological Theory, v. 7, n. 2, p. 177-200, 2007.

KALIVAS, Andreas. Politics and the Symbolic Foundations of Power in Max Weber. New German Critique, n 85, Special Issue on Intellectuals, p. 67-103, 2002.

LANA, L. A vítima oportunista: a construção da celebridade Luciana Gimenez. Interseções (UERJ), v. 15, p. 446-462, 2013.

LESLIE, L. Celebrity in the 21st Century: A Reference Handbook. Santa Barbara, CA: Greenwood, 2011.

LILTI, A. Figures publiques: l'invention de la célébrité. Paris: Fayard, 2014.

LOEWENSTEIN, K. Max Weber's Political Ideas in the Perspective of Our Time. Amherst: University of Massachusetts, 1966. 
MARSHALL, P. D. Celebrity and Power: Fame in Contemporary Culture. Minneapolis MN: University of Minnesota, 2008.

ORTIZ, R. As celebridades como emblema sociológico. Sociol. Antropol. Rio de janeiro, v. 6, n. 3, p. 669-697, 2016.

PYPE, K. Media Celebrity, Charisma and Morality in Post-Mobutu Kinshasa. Journal of Southern African Studies, v. 35, n. 3, p. 541-555, 2009.

ROJEK, C. Celebridade. Rio de Janeiro: Rocco, 2008.

RUEBSAAT, N. Seen by many: the celebrity image. In: Howell, Brian (org.). Fame us: celebrity impersonator and the culture of fame. Vancouver: Arsenal Pulp Press, 2007.

SELL, C. E. A secularização como sociologia do moderno: Max Weber, a Religião e o Brasil no contexto moderno-global. Revista Brasileira de Sociologia, v. 3, nº 6, p. 11-46, 2015.

SCHICKEL, R. Intimate Strangers: The Culture of Celebrity. New York: Doubleday, 1985.

SCHLESINGER, J. A. The structure of competition for office in the American States. Systems Research and Behavioral Science, v. 5, ed. 3, p. 197-210, 1960.

SHILS, A. E. Center and Periphery: Essays in Macrosociology. Chicago: University of Chicago Press, 1965.

STREET, J. Celebrity Politicians: Popular Culture and Political Representation. The British Journal of Politics \& International Relations, p. 435-52, 2004.

THOMPSON, J. The Media and Modernity: A Social Theory of the Media. Cambridge: Polity, 2005.

TUCKER, R. C. The Theory of Charismatic Leadership. Daedalus, v. 97, $n^{\circ} 3$, Philosophers and Kings: Studies in Leadership, p. 731-756, 1968.

TURNER, S. Charisma Reconsidered. Journal of Classical Sociology, v. 3, p. 5-26, 2003.

WEBER, M. Economia e Sociedade - Parte II: Fundamentos da sociologia compreensiva. UNB: Brasília, 2012.

WHEELER, M. The Democratic Worth of Celebrity Politics in an Era of Late Modernity. British Journal of Politics and International Relations, v. 14, p. 407-422, 2012.

Recebido em 18/07/2018.

Aprovado em 01/02/2020. 